\title{
Statistical Modeling for Stability of Emulsion Liquid Membrane for the Removal of Anionic Dyes from Textile Wastewater
}

\author{
RAJA FAHAD QURESHI*, KHADIJA QURESHI**, INAMULLAH BHATTI***, AND ZEESHAN KHATRI* \\ RECEIVED ON 28.09.2017 ACCEPTED ON 12.02.2018
}

\begin{abstract}
The importance of statistical modeling is obvious because it imparts an imperative role in predicting the effects of significant factors on any experimental process. In recent days, ELMs (Emulsion Liquid Membranes) are considered as an effective technique for the treatment of industrial wastewater. Despite of many advantages over the other treatment methods, ELM technology encounters one serious drawback of the stability of emulsion. The subject of this research is to identify the factors which are important to study the stability of ELM and also to evaluate the response of these parameters on stability. The membrane used in this study consisted of Span-80 and Hexane as surfactant and diluent respectively. The internal aqueous phase was $\mathrm{H}_{2} \mathrm{SO}_{4}$. The experimental setup was designed by using a well-known statistical approach of DoE (Design of Experiment) and the data was analyzed by Taguchi Method using a fractional factorial design. All the parameters including aqueous phase concentration, surfactant concentration, volume ratio of organic to aqueous phase, emulsification speed and emulsification time were selected as key factors to study their effect on the stability of ELM. Using different statistical techniques, it was found that emulsification speed and volume ratio of organic to aqueous phase are two most significant parameters. The significance level of these factors i.e. emulsification speed and volume ratio of organic to aqueous phase was statistically found as 99.7 and $\mathbf{9 9 . 9 \%}$ respectively. A statistical model was also developed and the experimental results were compared with estimated results. The value of correlation coefficient, $R^{2}$ was calculated as 0.997 indicating that the developed model fits the data very well.
\end{abstract}

Key Words: Design of Experiment, Emulsification, Emulsion Liquid Membrane, Stability.

\section{INTRODUCTION}

W

ater pollution caused by the industries is one of the chronic issues in these days worldwide [1]. Industries do not obey the environmental laws and never follow the EPA's (Environmental Protection Agency) rules and regulations in their states [2]. Direct discharge of wastewater into the water sources without any prior treatment is a routine practice of many industries. Amongst all these responsible industries, textile industry is also a major contributor of promoting environmental degradation globally. Wet

Authors E-Mail: (raja.ashraf@faculty.muet.edu.pk, khadija.qureshi@faculty.muet.edu.pk, inamullah.bhatti@faculty.muet.edu.pk, zeeshan.khatri@faculty.muet.edu.pk)

* Department of Textile Engineering, Mehran University of Engineering \& Technology, Jamshoro.

** Department of Chemical Engineering, Mehran University of Engineering \& Technology, Jamshoro.

*** Office of Research, Innovation and Commercialization, Mehran University of Engineering \& Technology, Jamshoro.

This is an open access article published by Mehran University Research Journal of Engineering and Technology, Jamshoro under the CC by 4.0 International License. 
Processing sector of textile industry consumes a huge quantity of water in many of its operations including dyeing, printing and finishing. Fresh water after being utilized in different processes is finally drained directly into the water bodies without any proper cleaning process. This textile wastewater usually contains a rich quantity of different contaminants in the form of hazardous chemicals, dyes and pigments [3]. Different classes of dyes are the major pollutant usually observed in the effluent released by any textile wet processing industry. It was reported [4] that $99 \%$ of the dyes used now-a-days in textile industry are of synthetic origin which contains different toxic and hazardous compounds in their basic structure. Toxic nature of these dyes imposes a carcinogenic and mutagenic effect on almost all the living species including humans, animals and aquatic fauna and flora [5]. Therefore, the treatment of textile wastewater contaminated with hazardous dyes is now-a-days one of the most serious environmental matter of thought for the industries as well as the researchers. Several methods for dye removal have been developed which includes biological treatments [6], coagulation/flocculation [7], chemical oxidation [8], adsorption [9] and photo catalytic processes [10]. However, with the ever upgrading of dye compounds in terms of their stability and solubility, these conventional methods tend to be rather ineffective or less efficient. In comparison to other treatment technologies, ELMs are considered as much efficient tool for the treatment of industrial wastewater containing various hazardous contaminants including dyes. ELMs provide high surface area which promotes better extraction of the target from source [11]. Another advantage of this technology is the possibility of extraction from very dilute solutions like dye solutions in many cases where dye presents in wastewater in a very small amount [11]. Inspite of having many advantages over the other treatment methods, the ELM technology encounters one serious drawback of the stability of emulsion. Stability in ELM system is generally considered as the resistance of the individual globules against coalescence [12]. In other words, it is the ability of emulsions to resist changes in physicochemical properties with time. Stability testing is an integral part of emulsion development work. Apart from their use in ELM system for wastewater treatment, emulsions encompass a vast number of everyday materials and products including foodstuffs, personal care items, and pharmaceuticals. Topical emulsions of both the $\mathrm{O} / \mathrm{W}$ (Oil-in-Water) and W/O) (Water-in-Oil) types are commonly used to improve aesthetics and ease of application. Emulsions may also be used to deliver multiple APIs (Active Pharmaceutical Ingredients) of differing solubility's, or present an API in a format that improves the distribution and/or permeation on application. In all these applications, the shelf life of the formulated emulsions is very crucial. Therefore, emulsion stability is monitored through stability testing before its use in particular application. However, as emulsions are inherently unstable, understanding the theoretical factors influencing emulsion stability is critical to study. Different factors play an impressive role in the stability of an ELM system. These factors may include surfactant concentration, concentration of different phases, volume ratios of the phases, emulsification speed and contact time [5]. The stability of emulsion liquid membranes is very important and it must be optimized before their use [13].

Most often, in order to determine the effect of different factors on the required response, conventional single factorial design method is used. In this method, one parameter is altered at different levels while the rest of the parameters are fixed at constant value. This parameter is then optimized and its value is set as constant while another parameter is varied. This method continues till all the operating parameters in the specific study are optimized. However, this method is not

Mehran University Research Journal of Engineering \& Technology, Volume 37, No. 3, July, 2018 [p-ISSN: 0254-7821, e-ISSN: 2413-7219] 
considered effective when the number of factors and their interactions are highly significant in the specific study [14]. In this case, the use of DoE is essential. In an experimental study, if all possible combinations of the levels for each operating parameter are performed, this method is called as Full Factorial Design. In full factorial design, method, the number of possible runs are usually calculated by simple formula of $(\mathrm{L})^{\mathrm{F}}$ where "L" represents the number of levels while "F" represents number of factors. This situation becomes quite complicated when the number of factors is very high. In this case, the fractional factorial design technique is used where the runs of a single part of the full factorial design provides the maximum required information. Using this experimental design, the coefficients for each parameter can be calculated along with its importance in the specific study. In this study, an approach of DoE was applied to determine the effect and significance of different parameters influencing the stability of an ELM. This ELM can subsequently be used for the extraction of anionic class of dyes from the industrial wastewaters. Anionic dyes are the most extensively utilized class of dyes in textile industry particularly in cotton textiles [15].

\section{EXPERIMENTAL}

\subsection{Reagents and Material}

The internal phase of the required ELM was prepared with $\mathrm{H}_{2} \mathrm{SO}_{4}$ (97\% purity) manufactured by Merck (Germany). Hexane and Sorbitan Monooleate commonly known as Span-80 were used as diluent and surfactant respectively to prepare organic phase. Hexane used in this research was the product of Fisher Scientific (UK) while Span-80 was purchased from local supplier manufactured by Sigma-Aldrich (USA). For membrane formation, ULTRA-TURRAX T-25 homogenizer made by IKA (Germany) was used to emulsify both the aqueous and organic phase. Homogenizer was attached with $18 \mathrm{G}$ mixing shaft operated at extremely higher homogenizing speed. This specially designed shaft was made of a hollow cylinder containing a rotor inside connected to a motor and stator with teeth on the outside. Wise Stir MSH-20D magnetic stirrer made by Witeg (Germany) was used to make aqueous and organic phases separately before emulsification.

\subsection{Procedure}

In order to make required stable membrane, both the aqueous and organic phases were separately prepared. Aqueous phase was made by dissolving an appropriate quantity of $\mathrm{H}_{2} \mathrm{SO}_{4}$ in distilled water to make solutions of different molarity. Organic phase was composed of Hexane as organic diluent and span-80 as surfactant. Both chemicals were mixed in an appropriate proportion and the solution was stirred and heated on WISE-STIR magnetic stirrer for 10 minutes at $30^{\circ} \mathrm{C}$ in a fixed stirring velocity of $700 \mathrm{rpm}$. Afterwards the organic phase was placed in $100 \mathrm{~mL}$ beaker and the aqueous phase was poured drop wise in it. The homogenizer shaft runs at a very high specified speed for some specific time. Afterwards the prepared emulsion was filled in scaled test tubes to determine the stability. The stability of ELM was determined by its constant behavior of dispensability and the uniform distribution of the dispersed phase with respect to time. The test tubes containing the prepared emulsion were placed in test tube holder and kept for 24-hours at normal room temperature $\left(25-30^{\circ} \mathrm{C}\right)$. After 24 -hours, the phase separation ratio of the aqueous and oil was calculated using the following expression [16]:

Stability $\%=\frac{\mathrm{Vt}-\mathrm{Vw}}{\mathrm{Vt}} \times 100$ 
Where $\mathrm{Vt}$ is the total volume of the emulsion in the test tube, and $\mathrm{Vw}$ is the separated volume of the aqueous phase in the test tube after 24 hours.

\subsection{Screening Design}

According to literature [17-18], parameters selected for the study of the membrane stability were concentration of aqueous phase, concentration of the surfactant, volume ratio of organic to aqueous phase, emulsification speed and emulsification time. The experiments were designed using DoE and analyzed through well-known Taguchi Method by using statistical software MINITAB-18. The minimum and maximum levels for each parameter were chosen after a literature review and specially after performing preliminary tests. Table 1 shows the list of parameters which influence the stability of ELM along with their minimum and maximum values. A completely randomized run order of fractional factorial design having 8 runs was generated and membrane was developed to study the effects of parameters on stability accordingly. Table 2 shows the experimental design and the experimental results of stability according to run order. Pareto chart of effects was used to identify the factors which are important in stability study and response of these parameters on the stability was analyzed with main effects plots. Pareto chart and Main Effect Plot are shown in Figs. 1-2 respectively.

TABLE 1. PARAMETERS AND LEVELS

\begin{tabular}{|c|c|c|c|}
\hline zNo. & Parameter & Minimum Level & Maximum Level \\
\hline 1. & Aqueous Phase Concentration (M) & 1 & 1 \\
\hline 2. & Surfactant Concentration (\%) & 1 & 2 \\
\hline 3. & Volume Ratio Organic/Aqueous & 3000 & 8000 \\
\hline 4. & Emulsification Speed (rpm) & 5 & 15 \\
\hline 5. & Emulsification Time (Minute) & & 5 \\
\hline
\end{tabular}

TABLE 2. EXPERIMENTAL RESULTS ACCORDING TO SCREENING DESIGN

\begin{tabular}{|c|c|c|c|c|c|c|}
\hline Run Order & $\begin{array}{l}\text { Aqueous Phase } \\
\text { Concentration }\end{array}$ & $\begin{array}{c}\text { Surfactant } \\
\text { Concentration }\end{array}$ & $\begin{array}{c}\text { Volume Ratio of } \\
\text { Organic/Aqueous } \\
\text { Phase }\end{array}$ & $\begin{array}{l}\text { Emulsification } \\
\text { Speed }\end{array}$ & $\begin{array}{c}\text { Emulsification } \\
\text { Time }\end{array}$ & Stability \\
\hline 1. & 0.1 & 1 & 1 & 3000 & 05 & 59.4 \\
\hline 2. & 0.1 & 1 & 1 & 8000 & 15 & 76.6 \\
\hline 3. & 0.1 & 5 & 2 & 3000 & 05 & 80.0 \\
\hline 4. & 0.1 & 5 & 2 & 8000 & 15 & 100.0 \\
\hline 5. & 1.0 & 1 & 2 & 3000 & 15 & 80.0 \\
\hline 6. & 1.0 & 1 & 2 & 8000 & 5 & 93.6 \\
\hline 7. & 1.0 & 5 & 1 & 3000 & 15 & 62.1 \\
\hline 8. & 1.0 & 5 & 1 & 8000 & 05 & 73.5 \\
\hline
\end{tabular}

Mehran University Research Journal of Engineering \& Technology, Volume 37, No. 3, July, 2018 [p-ISSN: 0254-7821, e-ISSN: 2413-7219] 


\section{RESULTS AND DISCUSSION}

The Pareto chart of effects is a useful field to identify the most important factors [19]. It shows the estimated main plot against the horizontal effect. Form Fig. 1 it is shown that the most important factors are volume ratio of organic to aqueous phase and emulsification speed. The rest of the parameters including aqueous phase concentration, surfactant concentration and emulsification time are less important. The interaction of surfactant concentration and emulsification time also affects the stability of the membrane but their effect is very minimum and almost negligible. Similar effects can also be observed from the interaction of surfactant concentration and emulsification speed which are also negligible.
Fig. 2 shows the main effect plot of parameters for stability of the required ELM. Main effect plot is also the most important tool used when there are several factors affecting any experimental system [20]. From Fig. 2, it can see that there are four out of five factors which have a positive effect on the stability of the emulsion. The positive effect of two factors i.e. volume ratio of organic to aqueous phase and emulsification speed is very high while the effect of surfactant concentration and Emulsification time is although positive but not very high. On the other hand, the effect of aqueous phase concentration is negative and very low.

Table 3 shows the coefficients and P-values of the parameters which affect the stability. The negative sign before the coefficient value identifies the negative effect

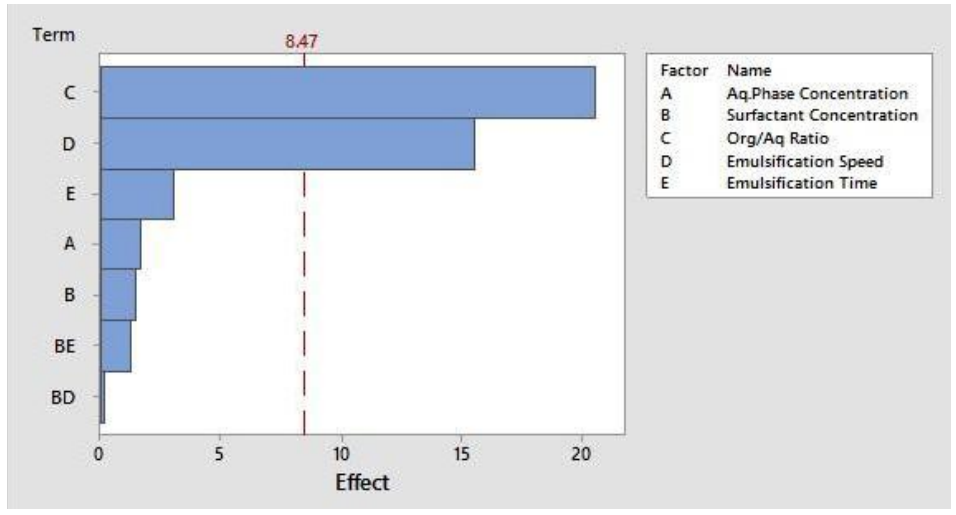

FIG. 1. PARETO CHART OF EFFECTS FOR STABILITY AS RESPONSE

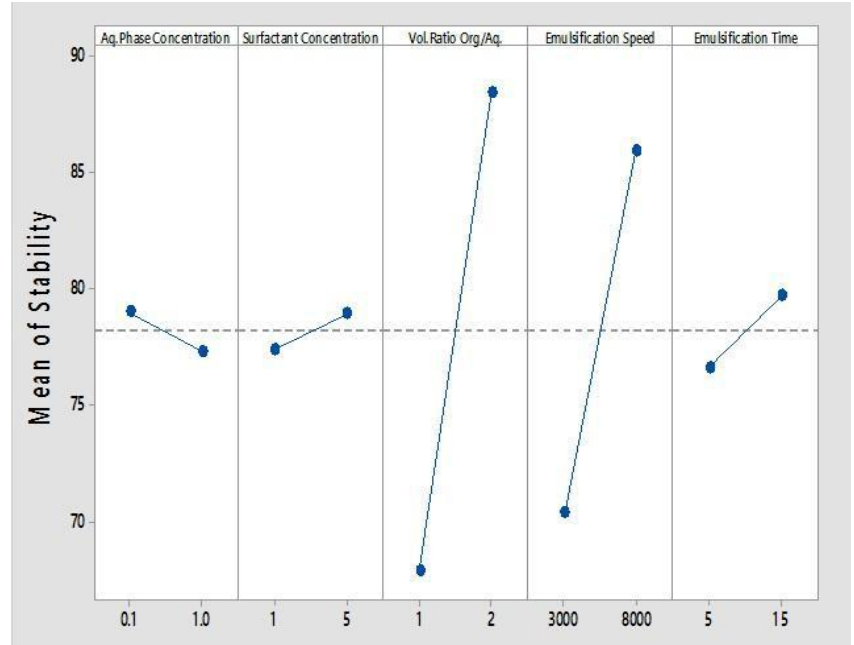

FIG. 2. MAIN EFFECT PLOT OF PARAMETERS FOR STABILITY

Mehran University Research Journal of Engineering \& Technology, Volume 37, No. 3, July, 2018 [p-ISSN: 0254-7821, e-ISSN: 2413-7219] 
of the corresponding parameter on the stability of the emulsion liquid membrane. P-value is a statistical parameter, used to determine the significance of the operating factors on any experimental system. If any effect is significant then there will be high probability that the effect is "real".

From Table 3, it can be seen that volume ratio of organic to Aqueous Phase has P-Value of 0.001 that means this parameter has $99.9 \%$ significance over the stability yield for this required ELM. Emulsification speed is the second most significant factor with significance level of $99.7 \%$.

\section{STATISTICAL MODEL FOR STABILITY OF ELM}

In order to facilitate the prediction of response and system optimization, the method of DoE also assists in developing a mathematical representation of the response according to all factors. Equation (2) represents the statistical model to observe the predicted response while varying the values of all the affecting parameters. This model was further used to determine the estimated results of stability according the screening design in Table 2 and these estimated results were compared with experimental results in Table 4.

$\begin{aligned} \text { Stability }= & 27.16-1.889(\text { Aq. Phase Concentration })+0.375 \\ & (\text { Surfactant Concentration }) \\ & +20.5(\text { Volume Ratio Org } / \text { Aq. Phase })+0.0031 \\ & (\text { Emulsification Speed }) \\ & +0.3050(\text { Emulsification Time })\end{aligned}$
Table 4 shows that the experimental and the predicted results are very close indicating that the model is very representative for the above study of membrane stability. Both the experimental and predicted values are plotted on graph in Fig. 3 and it can be seen that all the values (experimental and predicted) are fairly distributed around the regression line. The value of Correlation constant $\mathrm{R}^{2}$ was calculated as 0.997 indicating the excellence of fit and validation of the model.

TABLE 4. COMPARISON BETWEEN EXPERIMENTAL AND PREDICTED RESULTS

\begin{tabular}{|c|c|c|}
\hline Run Order & Experimental Results & Predicted Results \\
\hline 1 & 59.4 & 58.7 \\
\hline 2 & 76.6 & 77.3 \\
\hline 3 & 80.0 & 80.7 \\
\hline 4 & 100.0 & 99.3 \\
\hline 5 & 80.0 & 80.5 \\
\hline 6 & 93.6 & 93.0 \\
\hline 7 & 62.1 & 61.5 \\
\hline 8 & 73.5 & 74.0 \\
\hline
\end{tabular}

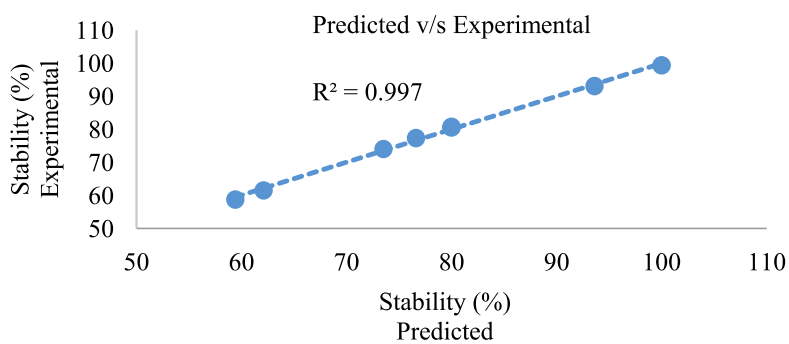

FIG. 3. CORRELATION BETWEEN PREDICTED AND EXPERIMENTAL RESULTS

TABLE 3. COEFFICIENTS AND P-VALUES OF PARAMETERS

\begin{tabular}{|c|c|c|c|}
\hline No. & Term & Coefficient & P-Value \\
\hline 1. & Intercept & 27.15888 & 0.006 \\
\hline 2. & Aqueous Phase Concentration & -1.88888 & 0.196 \\
\hline 3. & Surfactant Concentration & 0.375 & 0.234 \\
\hline 4. & Volume Ratio of Organic to Aqueous Phase & 20.5 & 0.001 \\
\hline 5. & Emulsification Speed & 0.00311 & 0.003 \\
\hline 6. & Emulsification Time & 0.305 & 0.075 \\
\hline
\end{tabular}

Mehran University Research Journal of Engineering \& Technology, Volume 37, No. 3, July, 2018 [p-ISSN: 0254-7821, e-ISSN: 2413-7219] 


\section{CONCLUSION}

In this study an approach of DoE was used to investigate the effect of operating parameters on the stability of ELM. $\mathrm{H}_{2} \mathrm{SO}_{4}$ was used as Stripping Agent in the Aqueous Phase while Hexane and Span-80 were used to formulate the Organic phase as Diluent and Surfactant respectively. This study showed that stability of the ELM requires certain operating conditions according to different important parameters. The experiments were designed using DoE and analyzed through well-known Taguchi Method by using statistical software MINITAB-18. A completely randomized run order of fractional factorial design having 8 runs was generated and membrane was developed to study the effect of all the operating parameters. Main effect Plot and Pareto chart revealed that volume ratio of organic to aqueous phase and emulsification speed are two most important parameters having high significance level. A statistical model was also developed and results of estimated and experimental values were compared. Correlation constant $\mathrm{R}^{2}$ value was calculated as 0.997 which indicated that the data fits the model well.This study would be helpful to overcome the main problem of stability associated with ELM systems and design a stable ELM for the extraction of anionic dyes from the wastewater.

\section{ACKNOWLEDGEMENT}

The authors acknowledge the facilities provided by Water Quality Lab. Department Chemical Engineering, Mehran University of Engineering \& Technology, Jamshoro, Pakistan, during the experimental work of this research. Authors also highly acknowledged to Mehran University of Engineering \& Technology, for providing financial support and required resources to carry out this research.

\section{REFERENCES}

[1] Reddy, D.H.K., "Water Pollution Control Technologies", Encyclopedia of Sustainable Technologies, Chapter-1, pp. 3-22, Oxford, 2017.

Shen, J., Wei, Y.D., and Yang, Z., "The Impact of Environmental Regulations on the Location of PollutionIntensive Industries in China", Journal of Cleaner Production, Volume 148, pp. 785-794, 2017.

Chen, L., Wang, L., Wu, X., and Ding, X., “A ProcessLevel Water Conservation and Pollution Control Performance Evaluation Tool of Cleaner Production Technology in Textile Industry", Journal of Cleaner Production, Volume 143, pp. 1137-1143, 2017.

[4] Chequer, F.M.D., Oliveira, G.A.R., Ferraz, E.R.A., Cardoso, J.C., Zanoni, M.V.B., and Oliveira, D.P., "Textile Dyes: Dyeing Process and Environmental Impact”, EcoFriendly Textile Dyeing and Finishing, Intech, Chapter-6, , pp. 503-561,2013.

[5] Dâas, A., and Hamdaoui, O., "Extraction of Anionic Dye from Aqueous Solutions by Emulsion Liquid Membrane", Journal of Hazardous Materials, Volume 178, pp. 973-981, 2010.

[6] Paz, A., Carballo, J., Pérez, M.J., and Domínguez, J.M., "Biological Treatment of Model Dyes and Textile Wastewaters", Chemosphere, Volume 181, pp. 168-177, 2017.

[7] Liang, C.-Z., Sun, S.-P., Li, F.-Y., Ong, Y.-K., and Chung, T.-S., "Treatment of Highly Concentrated Wastewater Containing Multiple Synthetic Dyes by a Combined Process of Coagulation/Flocculation and Nanofiltration”, Journal of Membrane Science, Volume 469, pp. 306-315, 2014.

[8] Soares, P.A., Souza, R., Soler, J., Silva, T.F.C.V., Souza, S.M.A.G.U., and Boaventura, R.A.R., "Remediation of a Synthetic Textile Wastewater from Polyester-Cotton Dyeing Combining Biological and Photochemical Oxidation Processes", Separation and Purification Technology, Volume 172, pp. 450-462, 2017. 
[9] Cretescu, I., Lupascu, T., Buciscanu, I., Balau-Mindru, T., and Soreanu, G., "Low-Cost Sorbents for the Removal of Acid Dyes from Aqueous Solutions", Process Safety and Environmental Protection, Volume 108, pp. 57-66, 2017.

[10] Natarajan, S., Bajaj, H.C., and Tayade, R.J., "Recent Advances Based on the Synergetic Effect of Adsorption for Removal of Dyes from Waste Water Using Photocatalytic Process", Journal of Environmental Sciences, Volume 8, pp. 38-45, 2017.

[11] Abbassian, K., and Kargari, A., "Modification of Membrane Formulation for Stabilization of Emulsion Liquid Membrane for Extraction of Phenol from Aqueous Solutions", Journal of Environmental Chemical Engineering, Volume 4, pp. 3926-3933, 2016.

[12] Sulaiman, R.N.R., Othman, N., and Amin, N.A.S., "Emulsion Liquid Membrane Stability in the Extraction of Ionized Nanosilver from Wash Water", Journal of Industrial and Engineering Chemistry, Volume 20, pp. 3243-3250, 2014

[13] Bahloul, L., Bendebane, F., Djenouhat, M., Meradi, H., and Ismail, F., "Effects and Optimization of Operating Parameters of Anionic Dye Extraction from an Aqueous Solution Using an Emulsified Liquid Membrane: Application of Designs of Experiments", Journal of the Taiwan Institute of Chemical Engineers, Volume 59, pp. 26-32, 2016

[14] Brahmia, N., Bouasla, C., Ismail, F., and Samar, M.E.H., "Recovery of 4-Chlorophenol from an Aqueous Solution by ELM: Stability of the Membrane, Modeling, and Optimization of the Extraction Using Experimental Designs", Desalination and Water Treatment, Volume 52, pp. 375-383, 2014
[15] Shukla, D., and Vankar, P.S., "4A-Dyeing of Cotton by Different New Natural Dyeing Sources", Natural Dyes for Textiles, Woodhead Publishing, pp. 111-140, 2017.

[16] Bhatti, I., Qureshi, K., Sozana, K., Bazmi, A.A., Bhutto, A., and Ahmad, F.,"Innovative Method to Prepare a Stable Emulsion Liquid Membrane for High $\mathrm{CO}_{2}$ Absorption and Its Performance Evaluation for a Natural Gas Feed in a Rotating Disk Contactor,, Journal of Natural Gas Science and Engineering Volume 34, 2016.

[17] Djenouhat, M., Hamdaoui, O., Chiha, M., and Samar, M.H.,"Ultrasonication-Assisted Preparation of Waterin-Oil Emulsions and Application to the Removal of Cationic Dyes from Water by Emulsion Liquid Membrane: Part-1: Membrane Stability", Separation and Purification Technology,Volume 62, pp. 636-641, 2008.

[18] Barad J. M., Chakraborty M., and Bart H.-J., "Stability and Performance Study of Water-in-Oil-in-Water Emulsion: Extraction of Aromatic Amines", Industrial \& Engineering Chemistry Research Volume 49, pp.5808$5815,2010$.

[19] Bahloul, L., Ismail, F., Samar, M.E.-H., and Meradi, H., "Removal of AY99 from an Aqueous Solution Using an Emulsified Liquid Membrane: Application of Plackettburman Design", Energy Procedia,Volume 50, pp. 10081016, 2014.

[20] Bahloul, L., Meriem, D., Bendebane, F., Meradi, H., and Ismail, F., "Effects of Parameters on the Extraction Yield of Acid Orange10 by ELM from an Aqueous Solution: Application of Plackett-Burman Design”, International Journal of Engineering \& Applied Sciences, Volume 2, 2015. 